Tohoku J. Exp. Med., 2006, 209, 285-289

\title{
Early Effects of Percutaneous Mitral Valvuloplasty on Left Atrial Mechanical Functions
}

\author{
Atila Bitigen, Muhsin Türkmen, Osman Karakaya, Mustafa Saglam, \\ Irfan Barutcu, Ali Metin Esen, Erdem Türkyilmaz, Ayhan Erkol, \\ Mustafa Bulut, Bilal Boztosun and Cevat Kirma \\ Department of Cardiology, Kartal Koşuyolu Yüksek Ihtisas Hospital Kartal, \\ Turkey
}

Bitigen, A., Türkmen, M., Karakaya, O., Saglam, M., Barutcu, I., Esen, A.M., Türkyilmaz, E., Erkol, A., Bulut, M., Boztosun, B. and Kirma, C. Early Effects of Percutaneous Mitral Valvuloplasty on Left Atrial Mechanical Functions. Tohoku J. Exp. Med., 2006, 209 (4), 285-289 — It has been suggested that successful percutaneous balloon mitral valvuloplasty (PMV) decreases the intensity of spontaneous left atrial contrast, reduces the size of the left atrium, and improves left atrial function in patient with mitral stenosis. However, left atrial mechanical functions immediately after PMV have not been extensively evaluated yet. The aim of this study was to evaluate the effects of PMV on left atrial mechanical functions. Twenty patients with critical mitral stenosis who have normal sinus rhythm (male/female: 4 to 16 ; mean age: $33 \pm 8$ years) were included in the study. Left atrial mechanical functions were evaluated before and after PMV, including left atrial passive emptying volume, LA passive emptying fraction, conduit volume, left ventricular stroke volume, LA active emptying volume, LA active emptying fraction, LA total emptying volume and LA total emptying fraction. PMV resulted in a significant increase in the mitral valve area $(p<0.001)$ and a substantial reduction in the mean transmitral pressure gradient $(p<0.001)$ as well as LA diameter $(p<0.002)$. LA maximal volume, minimal volume and atrial presystolic volumes were significantly decreased after PMV $(p: 0.001$; $p: 0.002 ; p: 0.001$, respectively). The conduit volume was increased and LA total emptying volume was decreased after PMV $(p: 0.014 ; p: 0.035)$. The other left atrial volumes were not altered after PMV. The early increase in conduit volume and the decrease in left atrial presystolic volume indicate that PMV has favorable effects on atrial reservoir and conduit functions. PMV therefore improves atrial mechanic functions. — left atrial mechanical functions; percutaneous mitral valvuloplasty; mitral stenosis

(C) 2006 Tohoku University Medical Press

Severe mitral stenosis (MS) leads to morphological and functional changes in left atrium as a consequence of volume and pressure loading and consequently left atrial (LA) dimension increases and LA pump function deteriorate as the time elapsed (Lin et al. 1995; Fukuchi et al. 2004;
Akdeniz et al. 2006; Uslu et al. 2006). Because it is well known that normal LA has a reservoir, conduit and pump function (Matsuda et al. 1983; Matsuzaki et al. 1991). On the other hand, percutaneous balloon mitral valvuloplasty (PMV) is a therapeutic option in selected patients with

Received February 27, 2006; revision accepted for publication May 15, 2006.

Correspondance: Atila Bitigen, M.D., TRT-Marmara Sitesi E-Blok No:10, Ulus/Besiktas, Istanbul, Turkey.

e-mail: bitigen@yahoo.com 
MS. Successful PMV decreases the intensity of spontaneous LA contrast, reduces the size of the LA, and improves LA function (Chiang et al. 1998). Although previous studies suggest that PMV improves LA appendage functions, LA mechanical functions immediately after PMV have not been extensively evaluated yet. Therefore, the purpose of this study was to evaluate the effect of PMV on LA mechanic functions by area length method in patients with MS following successful PMV.

\section{Material and Methods}

\section{Subjects}

A total of 20 patients with rheumatic MS (male/ female: 4 to 16 ; mean age: $33 \pm 8$ years) were included in the study. Those patients who fulfilled the PMV criteria and those who had experienced a successful intervention were included (Prendergast et al. 2002). Patients who did not accept transthoracic echocardiography after PMV, patients with hypertension, diabetes mellitus, congenital heart disease, atrial fibrillation, left ventricular systolic dysfunction, mitral prosthetic valve, aortic stenosis and a history of previous myocardial infarction and the patients who underwent a complication during the PMV and those who had an unsuccessful PMV were excluded from the study. The study protocol was approved by the ethics committee of Kartal Koşuyolu Yüksek Ihtisas Hospital and all patients gave their informed consent.

\section{Transthoracic echocardiography}

All participants underwent transthoracic echocardiography by an experienced research echocardiographer using commercially available echocardiographies equipped with 2.5-MHz transducer (Vivid System Five, GE Vingmed, Horten, Norway). Transthorasic echocardiography including the two-dimensional mode and Doppler echocardiographic studies were performed in the left lateral decubitus position with the conventional views (parasternal long and short axis, apical four chambers) according to the American Society of Echocardiography guidelines (Henry et al. 1980). On the parasternal long axis view, left ventricular end diastolic and end systolic diameters were measured by $\mathrm{M}$ mode and left ventricular ejection fraction was determined by using Teichholz method (Henry et al. 1980). Mitral valve area was calculated both by direct planimetric method on short axis view during diastole and by pressure half-time method (Hatle et al. 1978). The mean and peak diastolic transmitral pressure gradients were determined from apical 4-chamber view. Parameters measured with transthorasic echocardiography were measured once again on 72 hrs following PMV by the same expert operator.

\section{Left atrial mechanical function}

The functions of LA are (a) passive transport or conduit for pulmonary venous blood to the left venticle (LV) during ventricular diastole, (b) reservoir for storage of blood during ventricular systole and (c) active transport or pump function, that provides energy for filling LV beyond that provided by ventricular systole (Matsuda et al. 1983; Matsuzaki et al. 1991). Left atrial maximal volume (LAVmax) was measured just at the time of the opening of the mitral valve, left atrial minimal volume (LAVmin) was measured at the time of the closure of the mitral valve and the left atrial presystolic volume (LAVp) was measured synchronously with the start of the $\mathrm{P}$ wave on electrocardiography.

The left atrial volumes were measured on apical 4 and 2 chamber views using the area-length method and their average was taken. All volumes were corrected with respect to the body surface areas and left atrial functional parameters were calculated using the below mentioned formulas; 1 - LA passive emptying volume (LAPE $\mathrm{V})=\mathrm{LAVmax}-\mathrm{LAVp}$, 2- LA passive emptying fraction $(\mathrm{LAPEF})=\mathrm{LAPEV} / \mathrm{LAVmax}, 3$ - conduit volume $(\mathrm{CV})=$ Left ventricular stroke volume (LAVp- LAVmin), 4- LA active emptying volume (LAAEV) = LAVp- LAVmin, 5- LA active emptying fraction $(\mathrm{LAAEF})=\mathrm{LAAEV} /$ LAVp, 6- LA total emptying volume (LATEV) = (LAVmax -LAVmin), 7- LA total emptying fraction $($ LATEF $)=$ LATEV/LAmax (Toutouzas et al. 1996). All measurements were repeated during three consecutive beats and their average was taken. The reference values used to evaluate the mechanical function of the left atrium have been shown as normal values in Table 3 (Erol et al. 2001). The parameters showing the reservoir, conduit and pump functions of the left atrium respectively have also been shown separately in the Table 3 .

\section{Statistical analysis}

Statistical analysis was performed with SPSS for Windows 10.0 (SPSS Inc., Chicago, IL, USA). Values measured in our study were given as mean \pm S.D. For comparison of averages before and after PMV in the same group, matched student $t$-test was used. $P<0.05$ 
was accepted to make it meaningful.

\section{RESUltS}

All 20 patients had rheumatic valve disease etiology. NYHA functional capacity was class III in 13 cases and class II in 7 cases before PMV. Main characteristics of patients were shown in Table 1. After PMV, functional capacities were class I in 19 cases and class II in one case. Comparison of pre- and post-PMV transthoracic echocardiographic measurements was shown in Table 2. Left atrial passive emptying volume (LAPEV), LA passive emptying fraction (LAPEF), conduit volume, left ventricular stroke volume, LA active emptying volume (LAAEV), LA active emptying fraction (LAAEF), LA total

TABle 1. Patient demographic characteristics.

\begin{tabular}{lc}
\hline Variable & Value \\
\hline Age (year) & $33 \pm 8$ \\
Male & $4(20 \%)$ \\
Female & $16(80 \%)$ \\
Body surface area $\left(\mathrm{m}^{2}\right)$ & $1.67 \pm 0.16$ \\
Systolic blood pressure $(\mathrm{mmHg})$ & $130 \pm 9$ \\
Diastolic blood pressure $(\mathrm{mmHg})$ & $77 \pm 5$ \\
Heart rate (beat/min) & $74 \pm 9$ \\
\hline
\end{tabular}

emptying volume (LATEV) and LA total emptying fraction (LATEF) were measured. PMW resulted in a significant increase in the mitral valve area $(p<0.001)$ and a substantial reduction in the mean transmitral pressure gradient $(p<$ $0.001)$ as well as LA diameter $(p<0.002)$ (Table $2)$. LA maximal volume, minimal volume and atrial presystolic volumes were significantly decreased after PMV ( $p: 0.001 ; p$ : $0.002 ; p$ : 0.001 , respectively). The conduit volume was increased and LATEV was decreased after PMV ( $p$ : 0.014; $p$ : 0.035). However, the other left atrial volumes including LAPEV, LAPEF, LAAEV, LAAEF and LATEF were not altered after PMV (Table 3).

\section{Discussion}

In the present study we have shown that in patients with MS successful PMV improves LA reservoir and conduit functions but not the pump functions. We have also found that the successful PMV decreases transmitral gradient and increases valve area as well as stroke volume. These results were correlated with the fall in LA pressure (Basnight et al. 1991). In MS LA function may be disrupted due to increased LA afterload (Matsuda et al. 1983; Matsuzaki et al. 1991). It has been shown that LA afterload and the mean LA pressure decreases following PMV (Stefanadis

TABLE 2. Comparison of pre- and post-PMV values measured by transthoracic echocardiography.

\begin{tabular}{lccc}
\hline & Pre-PMV $(n=20)$ & Post-PMV $(n=20)$ & $p$ value \\
\hline LA $(\mathrm{cm})$ & $3.6 \pm 0.46$ & $2.49 \pm 0.68$ & 0.002 \\
EF $(\%)$ & $58 \pm 8.3$ & $63 \pm 6.9$ & NS \\
LVDD $(\mathrm{cm})$ & $4.46 \pm 0.4$ & $4.68 \pm 0.5$ & NS \\
LVSD $(\mathrm{cm})$ & $2.8 \pm 0.4$ & $2.8 \pm 0.4$ & NS \\
Mean Gr $(\mathrm{mmHg})$ & $8 \pm 5$ & $3 \pm 1.3$ & 0.001 \\
MVA $\left(\mathrm{cm}^{2}\right)$ pht & $0.7 \pm 0.2$ & $1.9 \pm 0.27$ & 0.001 \\
MVA $\left(\mathrm{cm}^{2}\right)$ plan & $1 \pm 0.2$ & $2.2 \pm 0.2$ & 0.001 \\
PAP $(\mathrm{mmHg})$ & $66 \pm 8$ & $41 \pm 9$ & 0.001 \\
SV (ml) & $54.8 \pm 15$ & $65.7 \pm 18$ & 0.002
\end{tabular}

LA, Left atrial diameter; EF, Left ventricular ejection fraction; LVDD, Left ventricular diastolic diameter; LVSD, Left ventricular systolic diameter; Max Gr, Mitral maximum gradient; Mean Gr, Mitral mean gradient; PMV, Percutaneous balloon mitral valvuloplasty; MVA pht, Pressure half time mitral valve area; MVA plan, Planimetric mitral valve area; PAP, Pulmonary artery pressure; SV, Stroke volume; NS, Not significant. 
TABLE 3. Comparison of pre- and post-PMV LA mechanic functional parameters measured by transthoracic echocardiography.

\begin{tabular}{ccccc}
\hline Variables & Pre-PMV $(n=20)$ & Post-PMV $(n=20)$ & $p$ value & Normal values \\
\hline LAVmax $\left(\mathrm{cm}^{3} / \mathrm{m}^{2}\right)$ & $58.8 \pm 7.9$ & $45.4 \pm 6.9$ & 0.001 & $16 \pm 5$ \\
LAVmin $\left(\mathrm{cm}^{3} / \mathrm{m}^{2}\right)$ & $39 \pm 6.9$ & $28 \pm 4.4$ & 0.002 & $6 \pm 2$ \\
LATEF $(\%)$ & $0.32 \pm 0.4$ & $0.37 \pm 0.4$ & $\mathrm{NS}$ & $0.66 \pm 0.11$ \\
LATEV $\left(\mathrm{cm}^{3} / \mathrm{m}^{2}\right)$ & $19.1 \pm 4.3$ & $16.7 \pm 4.4$ & 0.035 & $10 \pm 4$ \\
Reservoir function & & & & \\
LAVp $\left(\mathrm{cm}^{3} / \mathrm{m}^{2}\right)$ & $49.4 \pm 7$ & $37.7 \pm 5$ & 0.001 & $10 \pm 5$ \\
Conduit function & & & & \\
LAPEV $\left(\mathrm{cm}^{3} / \mathrm{m}^{2}\right)$ & $9.4 \pm 2.2$ & $8.3 \pm 2$ & $\mathrm{NS}$ & $6 \pm 3$ \\
LAPEF $(\%)$ & $0.16 \pm 0.2$ & $0.17 \pm 0.2$ & $\mathrm{NS}$ & $0.39 \pm 0.15$ \\
CV $\left(\mathrm{cm}^{3} / \mathrm{m}^{2}\right)$ & $22.6 \pm 5$ & $30.8 \pm 5.5$ & 0.014 & $30 \pm 13$ \\
Pump function & & & & \\
LAAEV $\left(\mathrm{cm}^{3} / \mathrm{m}^{2}\right)$ & $10.3 \pm 2$ & $9.7 \pm 2$ & $\mathrm{NS}$ & $4 \pm 3$ \\
LAAEF $(\%)$ & $0.22 \pm 0.3$ & $0.24 \pm 0.2$ & $\mathrm{NS}$ & $0.33 \pm 0.15$ \\
\hline
\end{tabular}

LAV max, Left atrial maximal volume $\left(\mathrm{cm}^{3} / \mathrm{m}^{2}\right) ; \mathrm{CV}$, Conduit volume $\left(\mathrm{cm}^{3} / \mathrm{m}^{2}\right)$; LAV min, left atrial minimal volume $\left(\mathrm{cm}^{3} / \mathrm{m}^{2}\right)$; LAV p, left atrial presystolic volume $\left(\mathrm{cm}^{3} / \mathrm{m}^{2}\right)$; LAPEV, LA passive emptying volume $\left(\mathrm{cm}^{3} / \mathrm{m}^{2}\right)$; LAPEF, LA passive emptying fraction (\%); LAAEV, LA active emptying volume $\left(\mathrm{cm}^{3} / \mathrm{m}^{2}\right)$; LAAEF, LA active emptying fraction (\%); LATEV, LA total emptying volume $\left(\mathrm{cm}^{3} / \mathrm{m}^{2}\right)$; LATEF, LA total emptying fraction (\%). NS, Not significant.

et al. 1998). In addition, Stefanadis et al. (1998) have suggested that PMV significantly decreases LA stiffness and increases he LA systolic emptying index and LA stroke. Also, following PMV reservoir function increased in the patients with atrial fibrillation but not in patients with sinus rhythm (Stefanadis et al. 1998). However, in this study, only patients with critical MS who have normal sinus rhythm were included and the LA mechanical functions were studied before and after PMV.

We observed that LAPEV, LAPEF, LAAEV, LAAEF did not improve completely following successful PMV. An early increase in CV and atrial presystolic volume indicates an improvement in reservoir and conduit functions. However, the pump function produced by the LA contraction in the late diastole did not improve in the early stages. Failure in the early complete improvement in atrial contraction may be thought to be due to the late improvements in anatomical changes such as fibrosis of atrial wall and disorganisation of atrial muscle bundles (Braunwald et al. 2005). Although different methods had been used, several previous reports studied diastolic function following PMV (Mohan et al. 1994; Krishnamoorthya and Dash 2004). Mohan et al. (1994) found that in younger patients with MS the decrease in atrial contribution is less than that in older patients. While the atrial contraction of young patients ( $<19$ years old) have recovered, there was no recovery in the left atrium functions of older age patients (Krishnamoorthya and Dash 2004). Younger patients achieved better atrial filling after PMV. This response is due to the improvement in atrial function, which is better in younger patients (Krishnamoorthya and Dash 2004). Pamir et al. (1997) suggested that although the left atrium pressure following PMV decreased, the early diastolic filling fraction of the left ventricle did not change, and the LV end diastolic pressure increased significantly after PMV. It has been concluded that the diastolic dysfunction did not recover at an early stage following PMV (Pamir et al. 1997). In our study, despite the increase of the valve area and the decrease of 
the left atrium, LA functions did not improve completely in the early stage after PMV.

\section{Conclusions}

The early increase in conduit volume and the decrease in left atrial presystolic volume indicate that PMV has favorable effects on atrial reservoir and conduit functions. Thus, PMV improves atrial mechanic functions.

\section{References}

Akdeniz, B., Badak, O., Baris, N., Aslan, O., Kirimli, O., Goldeli, O. \& Guneri, S. (2006) Left atrial appendage-flow velocity predicts cardioversion success in atrial fibrillation. Tohoku J. Exp. Med., 208, 243-250.

Basnight, M.A., Gonzalez, M.S., Kershenovich, S.C. \& Appleton, C.P. (1991) Pulmonary venous flow velocity: relation to hemodynamics, mitral flow velocity and left atrial volume and ejection fraction. J. Am. Soc. Echocardiogr., 4, 547-558.

Braunwald, E., Zipes, D.P., Libby, P. \& Bonow, R. (2005) Braunwald's heart disease: a textbook of cardiovascular medicine, 7th ed., Elsevier Saunders, Philadelphia, pp. $1553-1564$

Chiang, C.W., Lo, S.K., Ko, Y.S., Cheng, N.J., Lin, P.J. \& Chang, C.H. (1998) Predictors of systemic embolism in patients with mitral stenosis: a prospective study. Ann. Intern. Med., 128, 885-889.

Erol, M.K., Mahir, U.M., Yilmaz, M., Acikel, M., Sevimli, S. \& Alp, N. (2001) Left Atrial Mechanical Functions in Elite Male Athletes. Am. J. Cardiol., 88, 915-917.

Fukuchi, M., Kumagai, K., Sakuma, M., Kagaya, Y., Watanabe, J., Tabayashi, K. \& Shirato, K. (2004) Warfarin-intractable, intraatrial thrombogenesis in a 52-year-old woman with mitral stenosis and chronic atrial fibrillation. Tohoku J. Exp. Med., 203, 59-63.

Hatle, L., Brubakk, A., Tronsdal, A. \& Angelsen, B. (1978) Noninvasive assessment of pressure drop in mitral stenosis by doppler ultrasound. Br. Heart J., 40, 131-140.

Henry, W.L., DeMaria, A., Gramiak, R., King, D.L., Kisslo, J.A., Popp, R.L., Sahn, D.J., Schiller, N.B., Tajik, A., Teichholz, L.E. \& Weyman, A.E. (1980) Report of the American Society of Echocardiography Committee on nomenclature and standards in two dimensional echocardiography. Circulation., 62, 212-217.

Krishnamoorthya, K.M. \& Dash, P.K. (2004) Effect of age on atrial contribution to ventricular filling after balloon mitral valvuloplasty in mitral stenosis. Int. J. Cardiol., 96, 241-246.

Lin, J.M., Hsu, K.L., Hwang, J.J., Li, Y.H. \& Tseng, Y.Z. (1995) Effects of percutaneous mitral valvuloplasty on left atrial appendage flow velocity. Am. J. Cardiol., 76, 609-611.

Matsuda, Y., Toma, Y., Ogawa, H., Matsuzaki, M., Katayama, K., Fujii, T., Yoshino, F., Moritani, K., Kumada, T. \& Kusukawa, R. (1983) Importance of left atrial function in patients with myocardial infarction. Circulation., 67, 566-571.

Matsuzaki, M., Tamitani, M., Toma, Y., Ogawa, H., Katayama, K., Matsuda, Y. \& Kusukawa, R. (1991) Mechanism of augmented left atrial pump function in myocardial infarction and essential hypertension evaluated by left atrial pressure dimension relation. Am. J. Cardiol., 67, 1121-1126.

Mohan, J.C., Agrawal, R., Arora, R. \& Khalilullah, M. (1994) Atrial contribution to left ventricular filling in mitral stenosis: effects of balloon mitral valvuloplasty. Indian Heart J., 46, 129-132.

Pamir, G., Ertas, F., Oral, D., Gumus, F., Omurlu, K. \& Karaoguz, R. (1997) Left ventricular filling and ejection fraction after successful balloon mitral valvuloplasty. Int. J. Cardiol., 59, 243-246.

Prendergast, B.D., Shaw, T.R., Iung, B., Vahanian, A. \& Northridge, D.B. (2002) Contemporary criteria for the selection of patients for percutaneous balloon mitral valvuloplasty. Heart, 87, 401-404.

Stefanadis, C., Dernellis, J., Stratos, C., Tsiamis, E., Tsioufis, C., Toutouzas, K., Vlachopoulos, C., Pitsavos, C. \& Toutouzas, P. (1998) Assessment of left atrial pressure-area relation in humans by means of retrograde left atrial catheterization and echocardiographic automatic boundary detection: effects of dobutamine. J. Am. Coll. Cardiol., 31, 426-436.

Toutouzas, K., Trikas, A., Pitsavos, C., Barbetseas, J., Androulakis, A. \& Stefanadis, C. (1996) Echocardiographic features of left atrium in elite male athletes. Am. J. Cardiol., 78, 1314-1317.

Uslu, N., Nurkalem, Z., Orhan, A.L., Aksu, H., Sari, I., Soylu, O., Gurdogan, M., Topcu, K., Gorgulu, S. \& Eren, M. (2006) Transthoracic echocardiographic predictors of the left atrial appendage contraction velocity in stroke patients with sinus rhythm. Tohoku J. Exp. Med., 208, 291-298. 